\title{
Granulocyte-Monocyte Apheresis - Not the End of the Road Yet!
}

\author{
Stephan Vavricka \\ Abteilung für Gastroenterologie und Hepatologie, Stadtspital Triemli, Zürich, Schweiz
}

Immunomodulator therapy in patients with ulcerative colitis is often associated with subclinical reactivation of latent $\mathrm{CMV}$ infection. However, this reactivation is usually asymptomatic, or characterized by a mild, self-limited course. Serious tissue damage is rare but can cause end-organ damage such as CMV colitis. Several studies have suggested an association between infection with CMV and steroid- or therapy-resistant IBD and complications. CMV colitis mimicking an acute exacerbation of ulcerative colitis is associated with a poor outcome and a higher colectomy rate (ECCO statement OI 4A) [1]. Recommended treatment of CMV colitis includes prompt antiviral treatment with ganciclovir or other agents and discontinuation of immunosuppressive agents, but colectomy still cannot be avoided in every patient and new treatment strategies are needed.

Granulocyte-monocyte apheresis (GMA) has been suggested in many Japanese and European studies as a safe and effective treatment for ulcerative colitis. A pivotal, multicenter, randomized, sham-controlled US trial by Sands and colleagues [2,3], however, showed a lack of efficacy of GMA in patients with ulcerative colitis, and ever since then far fewer patients have been treated in the USA and Europe.

\section{KARGER \\ Fax +4161306 1234 E-Mail karger@karger.ch} www.karger.com
In the study by Yoshino et al. [4] presented in this journal, 64 patients with ulcerative colitis refractory to immunosuppressive therapies (such as steroids and immunomodulators) were retrospectively enrolled and the clinical outcomes of GMA and immunosuppressive therapy after 2 weeks of ganciclovir treatment were investigated. The total colectomy rate in ulcerative colitis patients positive for CMV was $36 \%$. This rate was lower in GMA-treated patients (2/11) compared to those treated with immunosuppressive therapy alone (5/9). The authors argue that GMA might be a safe and effective treatment for patients with ulcerative colitis positive for CMV because it does not induce CMV reactivation. This study is very promising since we have few treatment options in such patients. TNF- $\alpha$ antibodies such as infliximab may play a role, but only a few case reports have been published on the treatment of ulcerative colitis patients with concomitant CMV infection with conflicting results. Sure enough, the data presented in the study by Yoshino's group raise hopes that GMA is not at the end of its road but as the study of Sands and colleagues emphasized, rigorously designed trials with established endpoints should be the gold standard to determine efficacy of IBD therapy. Therefore, larger and if possible prospective studies are desperately needed. Until then one might consider using GMA in ulcerative colitis and concomitant CMV if this treatment is available.

Tel. +41 44466 1317, E-Mail stephan.vavricka@ triemli.stzh.ch 


\section{References}

1 Rahier JF, Ben-Horin S, Chowers Y, Conlon C, De Munter P, D’Haens G, Domènech E, Eliakim R, Eser A, Frater J, Gassull M, Giladi M, Kaser A, Lémann M, Moreels T, Moschen A, Pollok R, Reinisch W, Schunter M, Stange EF, Tilg H, Van Assche G, Viget N, Vucelic B, Walsh A, Weiss G, Yazdanpanah Y, Zabana Y, Travis SPL, Colombel JF: European evidence-based consensus on the prevention, diagnosis and management of opportunistic infections in inflammatory bowel disease on behalf of the European Crohn's and Colitis Organisation (ECCO). J Crohns Colitis 2009;3:47-91.
2 Sands BE, Sandborn WJ, Feagan B, Löfberg R, Hibi T, Wang T, Gustofson LM, Wong CJ, Vandervoort MK, Hanauer S, Adacolumn Study Group: A randomized double-blind, sham-controlled study of granulocytemonocyte apheresis for active ulcerative colitis. Gastroenterology 2008; 135:400409.
3 Gosh S, Kalan G, Panaccione R: Granulocyte-monocyte apheresis for the treatment of ulcerative colitis - is this the end of the road? Nat Clin Pract Gastroenterol Hepatol 2009; 6:6-7.

4 Yoshino T, Nakase H, Matsuura M, Matsumura K, Honzawa Y, Fukuchi T, Watanabe K, Murano M, Tsujikawa T, Fukunaga K, Matsumoto T, Chiba T: Effect and safety of granulocyte-monocyte adsorption apheresis for patients with ulcerative colitis positive for cytomegalovirus in comparison with immunosuppressants. Digestion 2011;84:3-9. 